\title{
Predicting teachers' generative and receptive use of an educational portal by intention, attitude and self-reported use
}

\author{
Bram Pynoo*, Johan van Braak \\ Ghent University, Faculty of Psychology and Educational Sciences, Department of Educational Studies, H. Dunantlaan 2, B-9000 Ghent, Belgium
}

\section{A R T I C L E I N F O}

\section{Article history:}

Available online $\mathrm{xxxx}$

\section{Keywords:}

Teachers' technology acceptance

Use behavior

C-TAM-TPB

Educational portal

Generative use behavior

Receptive use behavior

\begin{abstract}
A B S T R A C T
This study takes off where most acceptance studies stop, namely by investigating the link between acceptance and different aspects of actual usage of an educational portal. Both receptive (logins, downloads and pageviews) and generative use behavior (uploads and reactions) of 864 teachers was collected on two occasions, and linked to their responses on an acceptance questionnaire based upon C-TAM-TPB. Two research questions were put forward: (1) which dimensions of actual use are predicted by attitude, intention and self-reported use; and (2) can C-TAM-TPB discern uploaders from non-uploaders. Regression analyses showed that receptive use (logins, downloads, pages viewed) was predicted by attitude, intention and self-reported use (variance explained in the range .13-.16). Generative use (uploading and reacting) was not explained by these self-reported measures (Adj. $R^{2} .01$ and .04 ). Uploaders scored higher on all use parameters and almost all scales. A logistic regression showed that the more positive teachers' attitudes towards the portal and the higher their perceptions of control; the more likely they will upload information. This study is a call for more research on the factors that influence different dimensions of actual educational technology use, and should be an onset for more research on the link between intention and behavior in different settings, user populations, and technologies.
\end{abstract}

(c) 2014 Elsevier Ltd. All rights reserved.

\section{Rationale}

While introducing novel educational technologies to teachers, institutions are unsure as to whether the newly introduced technology will be adopted by the teachers, and used in the way the technology was designed to. For example, in the case of digital learning environments (DLE) that draw heavily on user-generated content, it is important to know (1) how teachers use the DLE: purely receptive (reading, consulting, downloading) or also generative (sharing knowledge or learning material), and (2) what actions can be undertaken so that teachers would make full use of the technology. These questions can be addressed through an acceptance study in which teachers' perceptions of a new technology are assessed. Guidelines to enhance use of the technology can then be devised based upon the findings of the acceptance study.

Acceptance studies have been applied in a range of settings, such as business (e.g. Venkatesh, Morris, Davis, \& Davis, 2003), health care (e.g. Pynoo et al., 2013) or education (e.g. Bourgonjon, De Grove, De Smet, Van Looy, Soetaert, \& Valcke, 2013; De Smet, Bourgonjon, De Wever, Schellens, \& Valcke, 2012; Pynoo et al., 2011a), studying a plethora of technologies, and hereby revealing interesting insights. However, they are also limited (Bagozzi, 2007 ) in that (a) technology use is regarded as a unidimensional

\footnotetext{
* Corresponding author. Tel.: +32 (0)477 4346 42; fax: +32 (0)9 2648688 .

E-mail address: BramPynoo@gmail.com (B. Pynoo).
}

phenomenon without taking the goal into account; and (b) the intention-behavior linkage is in most studies assumed, as actual use is in most studies not measured. This study aims to address these limitations by measuring different dimensions of educational technology use and by verifying which of them are significantly correlated with use intentions. Hereby, a distinction will be made between receptive use (logging in, browsing and downloading) and generative use (uploading, reacting on uploaded material) of the technology.

This study will contribute to the field of research in two respects: by coupling self-reported data to actual use and by explicitly taking into account that one technology can be used for very different purposes. As such, the results of this study should not only be valuable for researchers interested in explaining or predicting different aspects of teachers' ICT-usage, but also system administrators or portal owners who drawn on the users' of their technology to share information or knowledge.

\section{Theoretical background}

\subsection{Technology acceptance}

Acceptance models emerged from two distinct research traditions: on the one hand from base social psychology theories such as the Theory of Reasoned Action (Fishbein \& Ajzen, 1975) and 
the Social Cognitive Theory (Bandura, 1986), and on the other hand from sociology with the Diffusion of Innovations Theory (Rogers, 1995). An overview can be found in Venkatesh et al. (2003) or in Pynoo et al. (2013).

In the past, researchers put much effort in the search for the optimal set of variables to explain and predict acceptance. This resulted in a large number of models that were subsequently refined and modified. One line of models has dominated the field of research, those stemming from the Theory of Reasoned Action, with the Technology Acceptance Model (Davis, 1986; Davis, Bagozzi, \& Warshaw, 1989), the Theory of Planned Behavior (Ajzen, 1991) and the Unified Theory of Acceptance and Use of Technology (UTAUT) (Venkatesh et al., 2003) as most influential models or theories. UTAUT was conceived as the ultimate acceptance model, in which the most influential acceptance models were literally unified. According to UTAUT, technology acceptance (operationalized as behavioral intention and/or use) is regarded as a function of four core predictors: performance expectancy, effort expectancy, social influence and facilitating conditions. These predictors correspond with those in TAM and TPB, respectively perceived usefulness and perceived ease of use (TAM), and subjective norms and perceived behavioral control (TPB). There is one exception: attitude is omitted from UTAUT. With respect to attitude, there is a remarkable difference between acceptance research in educational settings and acceptance research in business (e.g. Venkatesh et al., 2003) or healthcare (e.g. Pynoo et al., 2013) settings. For educational researchers, attitude (or attitudes towards computers) is regarded as a key construct (e.g. Hermans, Tondeur, van Braak, \& Valcke, 2008; Mueller, Wood, Willoughby, Ross, \& Specht, 2008; Sang, Valcke, van Braak, \& Tondeur, 2010; Shapka \& Ferrari, 2003; van Braak, 2001), although some authors debate the role of attitude as mediating variable (Nistor \& Heymann, 2010; Teo, 2009a); whereas in business or healthcare settings it is regarded as a redundant in the presence of performance and effort expectancy (Venkatesh et al., 2003). Fig. 1 provides an overview of some recent acceptance studies in educational settings with in-service teachers. The technologies studied are either supportive educational technologies (such as DLE's) or computers in general. These studies are summarized in Table 1. Commonly, perceived usefulness is identified as the best and most consistent predictor of acceptance. The influence of perceived ease of use, subjective norms and perceived behavioral control on acceptance is in general less strong and inconsistent over the different studies. Next to these predictors stemming from TAM and TPB, self-efficacy, job relevance and technological complexity were also identified as predictors of acceptance (Gong, Xu, \& Yu, 2004; Hu, Clark, \& Ma, 2003; Teo, 2009a, 2009b).

In view of the significance of attitude for educational researchers and the review of the literature on educational technology acceptance studies (Fig. 1), it was decided to rely on a combination of the Technology Acceptance Model (TAM) - with attitude - and the Theory of Planned Behavior (TPB) for the purpose of this study. This model is depicted in Fig. 2.

\subsection{Measures for acceptance}

Acceptance models aim to explain or predict as much of the variance in use or user acceptance as possible. User acceptance can be defined as "the demonstrable willingness within a user group to employ information technology for the tasks it is designed to support" (Dillon \& Morris, 1996).

In sharp contrast with the large number of models that were developed and subsequently refined stands the relatively low attention for the identification of the most appropriate measures for acceptance. Several ways to measure technology acceptance have been proposed in the past. The most common operationalizations of acceptance are listed below.

\subsubsection{Use}

Use, either observed or self-reported, can be operationalized and measured in multiple ways, and actual use of a technology can be considered as a proof of acceptance. In most TAM-studies, observed use is either not measured, or only in a small number of respondents (Turner, Kitchenham, Brereton, Charters, \& Budgen, 2010). In the past, observed use has been measured as duration of use (Venkatesh et al., 2003), number of logins (Pynoo et al., 2011a) or by recording the actions a subject undertakes while completing a task (Shapka \& Ferrari, 2003). A problem with observed use is

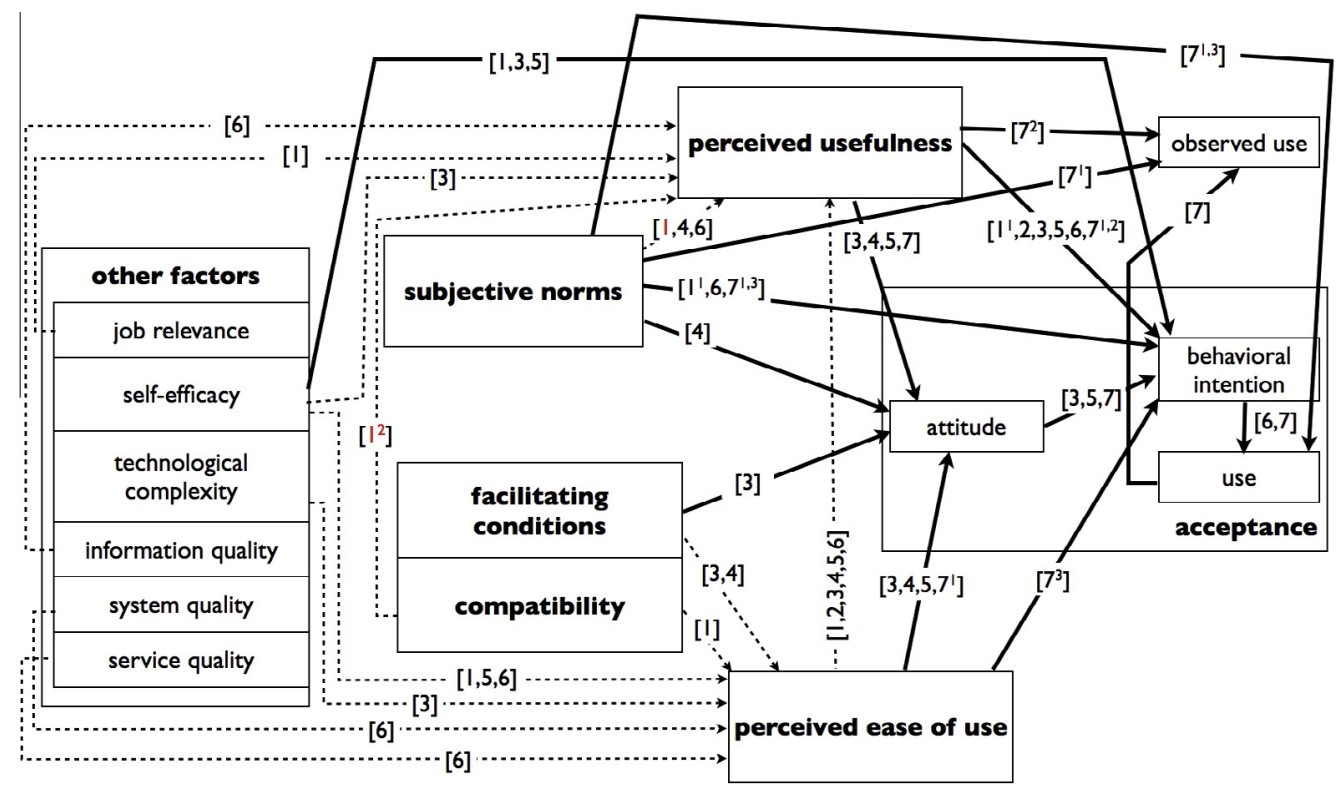

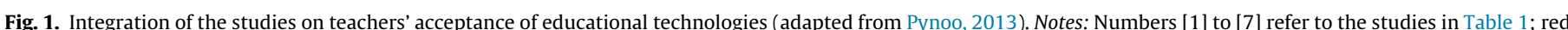

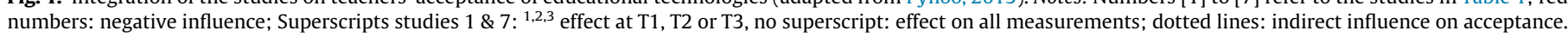
(For interpretation of the references to color in this figure legend, the reader is referred to the web version of this article.) 
Table 1

Overview of studies on teachers acceptance of educational technologies (adapted from Pynoo, 2012).

\begin{tabular}{|c|c|c|c|c|c|}
\hline & Educational technology & Population & Timing of the study & Model & $\begin{array}{l}\text { Dependent variable } \\
\text { (variance explained) }\end{array}$ \\
\hline $\begin{array}{l}\text { [1] Hu, Clark, } \\
\text { and Ma } \\
\text { (2003) }\end{array}$ & PowerPoint & $\begin{array}{l}\text { Teachers following a } \\
4 \text { week training program: } \\
N=138 \text { at } \mathrm{T} 1 ; 134 \text { at } \mathrm{T} 2\end{array}$ & $\begin{array}{l}\text { Beginning (T1) and end (T2) } \\
\text { of a training program }\end{array}$ & $\begin{array}{l}\text { TAM + job } \\
\text { relevance + compatibility } \\
+ \text { self-efficacy }\end{array}$ & $\begin{array}{l}\text { Intention } \\
\text { T1: }(.47) \\
\text { T2: }(.72)\end{array}$ \\
\hline $\begin{array}{l}\text { [2] Ma, } \\
\text { Andersson, } \\
\text { and Streith } \\
\text { (2005) }\end{array}$ & Computer & $\begin{array}{l}84 \text { Student teachers of a } \\
\text { Swedish university }\end{array}$ & Not specified & TAM2 & Intention (.43) \\
\hline $\begin{array}{l}\text { [3] Teo (2009a, } \\
\text { 2009b) }\end{array}$ & Computer & $\begin{array}{l}475 \text { Student teachers at a } \\
\text { teacher training institute }\end{array}$ & Not specified & $\begin{array}{l}\text { TAM + self- } \\
\text { efficacy + facilitating } \\
\text { conditions + technological } \\
\text { complexity }\end{array}$ & $\begin{array}{l}\text { Attitude }(.45) \\
\text { Intention }(.27)\end{array}$ \\
\hline $\begin{array}{l}\text { [4] Teo, Lee, and } \\
\text { Chai (2008) }\end{array}$ & Computer & 239 Pre-service teachers & Not specified & TAM3/UTAUT & Attitude (.42) \\
\hline $\begin{array}{l}\text { [5] Gong, Xu, } \\
\text { and Yu } \\
\text { (2004) }\end{array}$ & $\begin{array}{l}\text { Web-based learning } \\
\text { system }\end{array}$ & $\begin{array}{l}280 \text { Teachers in part-time } \\
\text { bachelor degree program }\end{array}$ & Not specified & TAM + self-efficacy & $\begin{array}{l}\text { Attitude }(.41) \\
\text { Intention }(.56)\end{array}$ \\
\hline $\begin{array}{l}\text { [6] Wang and } \\
\text { Wang (2009) }\end{array}$ & $\begin{array}{l}\text { Web-based learning } \\
\text { system }\end{array}$ & $\begin{array}{l}268 \text { Instructors of } 3 \\
\text { Taiwanese universities }\end{array}$ & Not specified & $\begin{array}{l}\text { TAM2 + self- } \\
\text { efficacy + Information, } \\
\text { System \& Service Quality }\end{array}$ & $\begin{array}{l}\text { Intention }(.69) \\
\text { System use }(.56)\end{array}$ \\
\hline $\begin{array}{l}\text { [7] Pynoo et al. } \\
\text { (2011a) }\end{array}$ & Intranet portal & $\begin{array}{l}\text { Teachers in one secondary } \\
\text { school: } N=64 \text { at T1; } 41 \text { at } \\
\text { T2; } 55 \text { at T3 }\end{array}$ & $\begin{array}{l}\text { At the introduction of the } \\
\text { technology (T1); } 2 \text { months } \\
\text { later (T2); } 9 \text { months after T1 } \\
\text { (T3) }\end{array}$ & $\begin{array}{l}\text { C-TAM-TPB + actual use: } \\
\text { number of logins into the } \\
\text { portal }\end{array}$ & $\begin{array}{l}\text { Attitude }(.78, .84, .76) \\
\text { Intention }(.35, .31, .38) \\
\text { S-r use }(.29, .16, .12) \\
\text { Actual use }(.08, .26, .11)\end{array}$ \\
\hline
\end{tabular}

Note: Numbers [1] to [7] are used in Fig. 1.

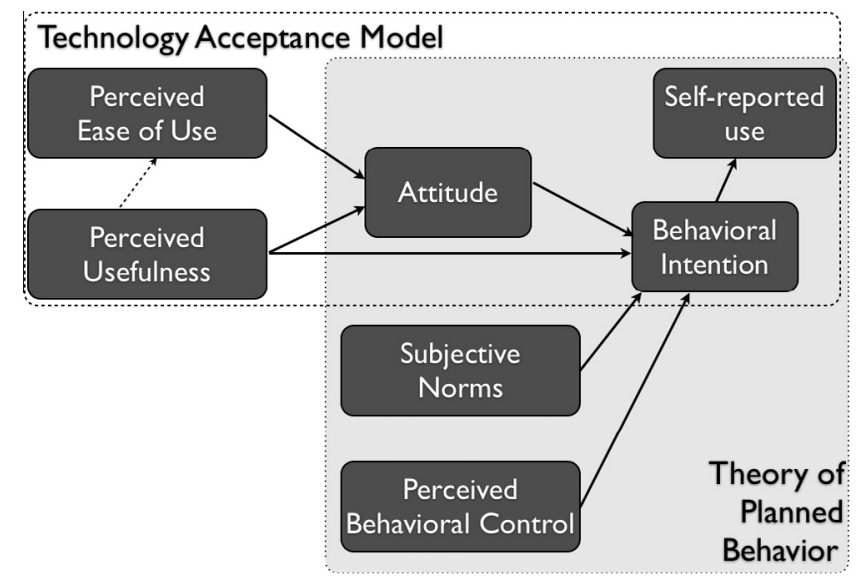

Fig. 2. Integration of the Technology Acceptance Model and the Theory of Planned Behavior into C-TAM-TPB.

that it requires subjects to have at least some experience with the technology. Collecting observed use parameters might also raise questions concerning the privacy of the respondents, which can be an issue, especially in hospital settings (e.g. Duyck et al., 2008a, 2008b). Self-reported use can be measured as frequency, duration, intensity (Pynoo et al., 2011b; Venkatesh, Brown, Maruping, \& Bala, 2008). Pynoo et al. (2011a) found self-reported frequency of use to be a good predictor of secondary school teachers' login behavior into their institutions intranet portal, on different occasions - and thus varying levels of experience with the portal - during the school year. Interestingly, in their study, behavioral intention and attitude were not predictive of teachers' login behavior.

\subsubsection{Behavioral intention}

TAM, TPB and the related models are also called intention-based models, as they take behavioral intention as the core measure for acceptance (Venkatesh et al., 2003). In this case behavioral intention serves as an antecedent to use (self-reported or observed) which is not always measured or taken into account in technology acceptance studies. Omitting use might threaten the validity of acceptance studies as evidenced by studies of Duyck et al. (2008a) and Pynoo et al. (2012a) in which behavioral intention did not predict self-reported use.

The appeal of intention as dependent variable is that intention, can be used in situations in which the technology has already been introduced (Pynoo et al., 2012b), but also, unlike observed use, for cases where it is still under planning (Duyck et al., 2008b). In most cases, items measuring behavioral intention are stated in a general manner, without specification of the nature of use, e.g. 'I intend to use $\langle$ the technology $\rangle$ in the next $\langle n\rangle$ months/weeks', with ample exceptions, e.g. Nistor, Schworm, and Werner (2012) who distinguished between receptive ('I intend to use the help system for information search in the next months') and active ('I plan to contribute to the further development of the help system in the next months') use intention. The limitations of behavioral intention as predictor of self-reported use in situations in which use of a technology has become a habit have been unveiled in several studies, e.g. Duyck et al. (2008a, 2008b), Nistor, Gögüs, and Lerche (2013) and Pynoo et al., 2013; Pynoo, et al., 2012a.

\subsubsection{Behavioral expectation}

This measure is closely related to and has frequently been confounded in the past with behavioral intention (Warshaw \& Davis, 1985a). Unlike intention, behavioral expectation requires respondents to think about conditions in which something might interfere between the intention and the actual performance of the behavior. Behavioral expectation has been found to correlate more strongly with behavior than behavioral intention (Warshaw \& Davis, 1985b), but it passed into disuse due to its conceptual overlap with behavioral intention (Warshaw \& Davis, 1985a). However, when used as a separate construct, next to behavioral intention, behavioral expectation adds to the prediction of use (Venkatesh et al., 2008). 


\subsubsection{Attitude toward use of the technology}

Attitude already appeared in the first version of TAM. The inclusion of attitude as a mediating variable between the predictor variables and behavioral intention has been debated throughout the years, also in educational settings (Nistor \& Heymann, 2010; Teo, 2009a). Consistent with Venkatesh et al. (2003), these authors argue that attitude does not improve the variance explained in technology use by the acceptance model as it is captured by perceived usefulness and perceived ease of use. Next to serving as a mediating variable, attitude has also been used as a measure for acceptance in both mandatory (Brown, Massey, Montoya-Weiss, \& Burkman, 2002; Pynoo et al., 2011a) and voluntary (Teo, Lee, \& Chai, 2008) settings. The appeal of attitude is that it does not require users to have hands-on experience with the technology, even not in the near future. Attitude may also prove valuable in situations in which use of a technology has become a habit: Pynoo et al. (2011a) found that unlike behavioral intention, attitude added - albeit marginally - to the prediction of actual use of an intranet portal when teachers had about one school year experience with using the portal.

\subsection{Research questions}

The primary assumption underlying acceptance models is that a user's intentions are predictive of his/her actual future behavior. This link will be scrutinized in this study in which teachers' acceptance of an educational portal will be coupled to their actual use of the portal. The first research question concerns the prediction of different aspects of portal use by different operationalizations of acceptance.

RQ1: to what extent can behavioral intention, attitude and selfreported (frequency and intensity of) use predict different kinds of actual use behavior (number of logins, downloads, uploads, pages viewed and reactions)?

For the second research question, we will investigate whether acceptance scales can make a distinction between teachers who upload and those who do not.

RQ2 to what extent can perceived usefulness, perceived ease of use, subjective norms, perceived behavioral control, attitude, behavioral intention and self-reported use discern between generative and non-generative users?

\section{Material and method}

\subsection{Technology: KlasCement}

The technology under study is an educational portal (www.klascement.net), targeted at Flemish and Dutch teachers, that builds upon user-generated content that is available for the other members of the portal under a creative commons license. This portal is supported by the Flemish Ministry of Education and is accessible to anyone who registers. The aim of KlasCement is to promote collaboration and communication between teachers regardless of their institution, or region. Use of the portal is on a voluntary basis. In a previous study Pynoo et al. (2012b) found that almost all teachers download content of the portal, whereas only a minority uploads information (exercises, lesson plans, pictures, etc.). There are limits to the number of learning material a member can download. Upon registration users receive a limited number of points that can be used to consult and download content of other portal members. Users can then earn points by sharing material. In order to maintain membership, portal members have to login at least once per year.

\subsection{Data collection and instruments}

The data for this study were collected as part of a larger portal evaluation survey. In March-April 2009, all portal members were invited to complete the survey. The acceptance part of the questionnaire was based upon C-TAM-TPB, see Fig. 2. Thus, the following predictor variables were measured: perceived usefulness, perceived ease of use, subjective norms and perceived behavioral control. Self-reported measures for acceptance were behavioral intention ("I intend to use KlasCement a lot in the following weeks"), attitude ("Using KlasCement is a good/bad idea"), self-reported frequency of use and self-reported intensity of use. Except for attitude (semantic differentials), self-reported frequency of use (' 1 ' = 'never', ' 6 ' = 'several times a day'), and self-reported intensity of use (' 1 ' = as few as possible', '7' = 'as much as possible') items had to be rated on 7-point Likert scales that were anchored between ' 1 : completely disagree' and '7: completely agree'."

Next to the self-reported data, observed use data was collected longitudinally on two occasions: upon completion of the questionnaire (T1), and about 22 months later (T2). The following use parameters were captured: number of logins, downloads, uploads, pages viewed and reactions (reactions on learning material or other information uploaded by a portal member) since the moment the member registered until T1 or T2. Demographic data (gender, age, role: teacher/parent/student/retired/other) was also extracted from the database.

\subsection{Sample}

All members of KlasCement were invited to participate in this study. At the start of the study (T1, March 2009), KlasCement had over 40,000 members, mostly female (64\%). The survey was completed by 1139 respondents. For this study, only portal members who (a) indicate that they are teachers, and (b) whose observed use could be collected at both $\mathrm{T} 1$ and $\mathrm{T} 2$ are withheld. This led to a final sample of 864 teachers: 605 female (70\%) and 259 male (30\%) teachers, which closely corresponds with the entire population in March 2009: 64\% female and 36\% male members.

\subsection{Data analysis}

All analyses are performed in SPSS 20. Prior to the analysis of the research questions, descriptive statistics (scale means and standard deviations) are calculated. Independent samples $t$-tests are used to compare the mean scores of male and female teachers, and of uploaders and non-uploaders. Through a linear regression analysis, we investigate whether the self-reported measures of acceptance can be predicted through C-TAM-TPB. Then the two research questions are addressed. For the first research question, the prediction of observed use parameters by the self-reported measures of acceptance, linear regressions per use parameter are run. For the second research question, a logistic regression is used to investigate whether the variables of C-TAM-TPB can distinguish between uploaders and non-uploaders.

\section{Results}

\subsection{Descriptive statistics}

First, descriptive statistics are calculated. These are displayed in Table 2. Next to an overall mean, we also investigate whether differences can be observed between male and female teachers, and between uploaders and non-uploaders.

Teachers evaluate the portal as quite useful and easy to use, without pressure from the social environment to use the portal. 
Teachers also experience a large amount of control over their use of the portal. With regard to the acceptance measures, teachers hold a positive attitude towards use of the portal and they intend to keep on using the portal. The mean score on frequency of use is close to three, which corresponds with the response 'During a regular school week, I use the portal about once a week'. This is confirmed by the observed use data at T2: on average, teachers log in 3.82 times per month, which is close to once a week. The negative amount of reactions per month is at first sight counterintuitive, yet it is due to the way the use parameters are calculated (number of reactions at $\mathrm{T} 2$ minus those at $\mathrm{T} 1$ ) and because reactions are removed if the associated contribution/material is removed. From Table 2 we can conclude that consistent with the findings at T1 (Pynoo et al., 2012b) teachers use the portal at T2 also more frequently in a receptive (logging in, browsing and downloading) rather than a generative (uploading, reacting) manner.

Only few differences are observed between male and female teachers. Female teachers are on average younger and their duration of membership was shorter compared to the male teachers. Male teachers evaluate the portal as easier to use, and experience somewhat more pressure from their environment. Female teachers on the other hand hold a more positive attitude towards using the portal, and they have a stronger intention to use the portal. Female teachers are also heavier downloaders.

Comparing uploaders and non-uploaders, large differences are observed. Uploaders score higher on all predictor variables (except for subjective norms), higher on the self-reported measures for acceptance and higher on the use parameters. With regard to the demographics, we see that male and female teachers are equally distributed between the two groups $\left(\chi^{2}(1)=1.453, p=.23\right)$. In terms of age and duration of membership, we find that uploaders are significantly younger and their duration of membership is significantly longer than non-uploaders.

\subsection{Prediction of user acceptance}

Table 3 reports the results of the linear regression analyses limited to self-reported measures of acceptance as in classical acceptance studies (such as the studies listed in Table 1) in which actual use of the technology was not (or could not be) measured. Perceived usefulness is the strongest predictor of attitude $(\beta=.51, p<.001)$ and behavioral intention $(\beta=.55, p<.001)$. Perceived ease of use is also a significant predictor of attitude ( $\beta=.25, p<.001)$ yet less strong than perceived usefulness; whereas norms and perceived behavioral control are of no importance. Variance explained in attitude (Adj. $R^{2} .43$ ), intention (Adj. $R^{2}$ $.50)$ and intensity of use (Adj. $R^{2} .49$ ) is quite high, whereas the variance explained in self-reported frequency of use is somewhat lower (Adj. $R^{2} .29$ ). From Table 3 it would be straightforward to conclude that if teachers evaluate the portal as useful and easy to use, they will in the end use the portal more frequently, without specification of the purpose of use. This is investigated in Section 4.3.

\subsection{RQ1: prediction of actual use behavior}

The regression analyses (see Table 4) show that attitude, intention and self-reported frequency of use predict downloading, browsing and logging in behavior, with self-reported frequency of use as strongest predictor. Variance explained in actual use is however quite low (.13-.16). Generative behavior (uploading information or commenting on uploaded material) is not predicted by intention or attitude; only by self-reported frequency of use, and variance explained is very low (.01 and .04). Teachers' gender is related to uploading and downloading: male teachers are more likely to upload $(\beta=.07, p<.05)$ whereas female teachers are more likely to download $(\beta=-.13, p<.001)$.

\subsection{RQ2: uploaders vs. non-uploaders}

Descriptive statistics in Table 2 showed that uploaders not only evaluate the portal more positively and score higher on the acceptance measures, yet also that they use the portal more frequently compared to non-uploaders. In the previous paragraph, we found that the amount of uploads cannot be predicted through C-TAMTPB. For the second research question we were interested as to whether the scales of C-TAM-TPB can distinguish between teachers who share material and those who do not. A dummy variable was created to distinguish the "uploaders" from the "non-uploaders". This variable served as dependent variable for the logistic regression. The results of this analysis are in Table 5.

Table 5 shows that uploading is associated with holding a positive attitude towards use of the portal, and that teachers are more likely to contribute if they have more control over their behavior (=using the portal). Variance explained was rather low (Nagelkerke $\left.R^{2} .09\right)$.

\section{Discussion}

\subsection{Descriptive statistics}

Descriptive statistics (Table 2) revealed quite some significant differences between teachers who share learning material (uploaders) and teachers who do not share (non-uploaders). Based upon these findings, it could be argued that teachers who upload are innovators or early adopters in terms of Rogers (1995) who are better informed and more aware of the latest educational innovations, and who are more skilled in using the computer. Consistent with Pynoo et al. (2012b), these findings also indicate that it makes more sense to categorize technology users based upon their use profile rather than on their gender.

\subsection{Prediction of user acceptance}

In a preliminary analysis we conducted a typical acceptance study: prediction of different acceptance measures with C-TAMTPB as theoretical framework. The findings of these regression analyses are consistent with what is commonly observed in the literature (e.g. Gong et al., 2004; Hu et al., 2003; Ma, Andersson, \& Streith, 2005; Teo, 2009b; Teo et al., 2008; Wang \& Wang, 2009): perceived usefulness is the strongest predictor of attitude and behavioral intention; whereas the other predictor variables are of minor or no importance. Variance explained in attitude, intention and intensity of use is comparable to what is commonly observed, variance explained in frequency of use is somewhat lower. In their review of TAM-studies, Turner et al. (2010) observed that the relationships between independent and dependent variables seem to weaken along the attitude-intention-behavior chain. For example, the relationships between attitude and intention are in general weaker than the relationship between intention and use. This is not the case here; the relationship between attitude and self-reported frequency of use is stronger than that between attitude and intention. This might be explained by the population (in-service teachers) and the specificity of the technology (job-relevant yet completely voluntary; open for everybody yet one has to enroll). Enrolled teachers know why they use (or keep on using) the portal, namely primarily to download information and learning material. Therefore only teachers who hold positive attitudes towards use of the portal will retain their membership and will not only intend to but also use the portal more frequently. 
Table 2

Descriptive statistics: Mean and standard deviation, overall, per gender and uploaders vs non-uploaders.

\begin{tabular}{|c|c|c|c|c|c|c|c|}
\hline & \multirow{2}{*}{$\begin{array}{l}\text { Overall } \\
\text { Mean (SD) }\end{array}$} & \multicolumn{3}{|l|}{ Gender } & \multicolumn{3}{|c|}{ Generative use: uploading? } \\
\hline & & $\begin{array}{l}\text { Female } \\
\text { Mean (SD) }\end{array}$ & $\begin{array}{l}\text { Male } \\
\text { Mean (SD) }\end{array}$ & Sig. level $t$-test ${ }^{\mathrm{a}}$ & $\begin{array}{l}\text { No } \\
\text { Mean (SD) }\end{array}$ & $\begin{array}{l}\text { Yes } \\
\text { Mean (SD) }\end{array}$ & Sig. level $t$-test ${ }^{\mathrm{b}}$ \\
\hline$N$ (female/male) & 864 & 605 & 259 & $\mathrm{~N} / \mathrm{A}$ & $602(429 / 173)$ & $262(176 / 86)$ & $\mathrm{N} / \mathrm{A}$ \\
\hline Age & $39.6(10.4)$ & 37.8 (9.99) & $43.8(10.3)$ & $p<.001$ & $40.4(10.4)$ & $37.7(10.4)$ & $p<.001$ \\
\hline Months of membership (T1) & $25.2(16.9)$ & $24.4(16.1)$ & $27.1(18.4)$ & $p=.04$ & $23.5(16.2)$ & $29.1(17.8)$ & $p<.001$ \\
\hline Perceived usefulness & $4.68(1.32)$ & $4.73(1.32)$ & $4.57(1.31)$ & $p=.10$ & $4.57(1.30)$ & $4.93(1.32)$ & $p<.001$ \\
\hline Perceived ease of use & $5.02(1.50)$ & $4.93(1.57)$ & $5.22(1.30)$ & $p=.005$ & $4.84(1.54)$ & $5.43(1.33)$ & $p<.001$ \\
\hline Subjective norms & $1.40(0.64)$ & $1.33(0.57)$ & $1.57(0.77)$ & $p<.001$ & $1.41(0.65)$ & $1.38(0.63)$ & $p=.50$ \\
\hline Perceived behavioral control & $6.16(0.86)$ & $6.15(0.81)$ & $6.17(0.95)$ & $p=.79$ & $6.06(0.87)$ & $6.38(0.79)$ & $p<.001$ \\
\hline Behavioral intention & $4.31(1.52)$ & $4.43(1.52)$ & $4.03(1.50)$ & $p<.001$ & $4.15(1.49)$ & $4.68(1.54)$ & $p<.001$ \\
\hline Use - frequency & $2.95(0.91)$ & $2.95(0.91)$ & $2.95(0.91)$ & $p=.93$ & $2.88(0.88)$ & $3.11(0.97)$ & $p=.001$ \\
\hline Use - intensity & $4.15(1.46)$ & $4.20(1.49)$ & $4.06(1.41)$ & $p=.21$ & $4.01(1.44)$ & $4.50(1.47)$ & $p<.001$ \\
\hline Attitude & $5.96(0.95)$ & $6.01(0.94)$ & $5.86(0.95)$ & $p=.03$ & $5.84(0.97)$ & $6.25(0.83)$ & $p<.001$ \\
\hline Logins per month (T2) & $3.82(8.23)$ & $3.75(5.89)$ & $3.99(12.1)$ & $p=.69$ & $2.42(3.61)$ & $7.03(13.4)$ & $p<.001$ \\
\hline Uploads per month (T2) & $0.06(0.50)$ & $0.03(0.21)$ & $0.11(0.85)$ & $p=.17$ & $0.00(0.00)$ & $0.19(0.89)$ & $p=.001$ \\
\hline Downloads per month (T2) & $7.14(12.5)$ & $8.38(13.6)$ & $4.25(8.81)$ & $p<.001$ & $5.40(8.85)$ & $11.1(17.7)$ & $p<.001$ \\
\hline Reactions per month (T2) & $-0.09(0.39)$ & $-0.10(0.43)$ & $-0.08(0.24)$ & $p=.36$ & $-0.03(0.12)$ & $-0.24(0.65)$ & $p<.001$ \\
\hline Pageviews per month (T2) & $43.7(77.4)$ & $46.2(66.2)$ & $37.9(98.8)$ & $p=.15$ & $28.6(41.1)$ & $78.4(119.2)$ & $p<.001$ \\
\hline
\end{tabular}

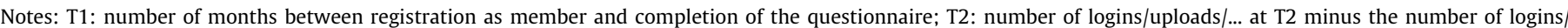
uploads/... at T1 per month between T1 and date of last login.

a Independent samples $t$-test comparing female and male teachers.

b Independent samples $t$-test comparing uploaders (Yes) and non-uploaders (No).

Table 3

Result of linear regressions with self-reported measures of acceptance as dependent variables. Values reported are standardized $\beta$ regression coefficients.

\begin{tabular}{|c|c|c|c|c|}
\hline & Attitude & Behavioral intention & Self-reported frequency of use & Self-reported intensity of use \\
\hline Perceived ease of use & $.25^{* * * *}$ & & & \\
\hline Perceived usefulness & $.51^{* * * *}$ & $.55^{* * *}$ & & \\
\hline Attitude & & $.21^{* * * *}$ & $.15^{* * *}$ & $.31^{* * * *}$ \\
\hline Subjective norms & & $.04^{\circ}$ & & \\
\hline Perceived behavioral control & & -.02 & & \\
\hline Behavioral intention & & & $.44^{* * *}$ & $.47^{* * *}$ \\
\hline Adj. $R^{2}$ & .43 & .50 & .29 & .49 \\
\hline
\end{tabular}

**** $p<.001$

$p<.10$.

Table 4

Prediction of actual use parameters (RQ1).

\begin{tabular}{|c|c|c|c|c|c|}
\hline & \multicolumn{3}{|c|}{ Receptive use } & \multicolumn{2}{|c|}{ Generative use } \\
\hline & Logins & Downloads & Pageviews & Uploads & Reactions \\
\hline Attitude & $.07^{\circ}$ & $.08^{*}$ & $.08^{\circ}$ & -.05 & -.07 \\
\hline Behavioral intention & .04 & $.13^{*}$ & $.10^{*}$ & .01 & -.03 \\
\hline Use - frequency & $.31^{* * * *}$ & $.28^{* * * *}$ & $.32^{* * *}$ & $.10^{*}$ & $-.13^{* *}$ \\
\hline Use - intensity & -.02 & -.04 & -.03 & -.04 & -.02 \\
\hline Gender & .02 & $-.13^{* * *}$ & -.03 & $.07^{*}$ & .02 \\
\hline $\operatorname{Adj} R^{2}$ & .13 & .16 & .16 & .01 & .04 \\
\hline Significance level model test $[F(5,558)]$ & $p<.001$ & $p<.001$ & $p<.001$ & $p=.02$ & $p<.001$ \\
\hline
\end{tabular}

**** $p<.001$

*** $p<.01$.

* $p<.05$.

$p<.10$.

\subsection{RQ1: prediction of actual use behavior}

The self-reported measures for acceptance were found to predict different aspects of receptive use of the portal (number of logins, downloads, pages viewed). Variance explained in these use parameters was between $13 \%$ and $16 \%$, which is rather low. The strongest predictor of receptive portal-use is self-reported frequency of use. Generative use behavior (number of uploads, reactions on uploaded material) could hardly be predicted by attitude, intention or self-reported use; variance explained was very low (.01 and .04). With this analysis, we showed that when teachers indicate they (will) use a novel technology, this means that they will access the technology and get information from it, but not necessarily share their knowledge. So, acceptance models may be limited when it comes to the prediction of teachers' usage of educational technologies that draw heavily on user generated content, such as Web 2.0 applications. 
Table 5

Results of logistic regression analysis (RQ2).

\begin{tabular}{lc}
\hline & Uploading (No/Yes) \\
\hline Perceived usefulness & -.14 \\
Perceived ease of use & .10 \\
Subjective norms & -.13 \\
Perceived behavioral control & $.27^{*}$ \\
Behavioral intention & .11 \\
Use - frequency & .03 \\
Use - intensity & .05 \\
Attitude & $.34^{* *}$ \\
Nagelkerke $R^{2}$ & .09 \\
\hline
\end{tabular}

*** $p<.01$.

$p<.05$.

\subsection{RQ2: uploaders vs. non-uploaders}

KlasCement draws heavily on their members to share learning material or other information with the other members of the portal, yet only a minority of the teachers uploads some learning material or other information (monthly average of uploads is 0.06). The logistic regression showed that uploading is associated with holding a positive attitude towards use of the portal, and that teachers who have more control over their behavior (perceived behavioral control) are more likely to contribute. According to TAM (Davis et al., 1989), attitude is a function of perceived usefulness and ease of use: teachers who are better aware of the possibilities and features of the portal, and who are more skillful in using the portal will hold a higher attitude towards the portal. Perceived behavioral control has to do with knowledge (on how to operate a computer) and infrastructure (computer and Internet). Teachers who are better equipped and more aware on how to operate are also more likely to contribute their own material. These are also indications that uploaders can be referred to as early adopters (Rogers, 1995) who are welcoming new technologies and are quite literate in operating these new technologies.

\subsection{Limitations}

The main limitation of this study is that personal characteristics of the teachers (course, education level, education system, employment) could not be taken into account as these characteristics were not extracted from the database. A second limitation of this study pertains to the calculation of the number of uploads: all uploads were aggregated and we could not distinguish between learning material and other information (e.g. calendar items). We assume that by taking the personal characteristics of teachers into account, and by limiting the number of uploads to learning material, that we would have a better view on why teachers upload information, and on what actions to undertake to foster generative use behavior.

\section{Conclusion}

This study takes off where most acceptance studies stop, namely by investigating the link between acceptance and different aspects of actual technology usage. Hereto, questionnaire data of 864 teachers/members of KlasCement - an educational portal was coupled to their use data extracted from the portal's logs. Acceptance was measured as behavioral intention, attitude, and self-reported frequency and intensity of use, whereas five use parameters were extracted: the number of logins, downloads, uploads, pages viewed and reactions on uploaded material. The portal is built upon user generated content, yet only a minority of the teachers shares material. Uploaders and non-uploaders differ fundamentally from each other: uploaders' perceptions of the portal are more positive, they score higher on the acceptance measures, and use the portal more and more frequently than the non-uploaders. The logistic regression showed - although variance explained was rather low - that if teachers hold a higher attitude towards the portal and have higher perceptions of control, they are more likely to be uploaders.

This study showed that technology acceptance models can predict actual use of an educational technology, yet limited to receptive use. As such, this study should be an onset for more research on the factors that can explain teachers' generative use behavior through educational technologies. Large differences between uploaders and non-uploaders were observed that could not be accounted for by C-TAM-TPB. Therefore, a second direction for follow-up research is on the factors that distinguish the uploaders from the non-uploaders. Including more person-related variables (e.g. a measure of personality or technology readiness) might prove fruitful in this vein, see for example Devolder, Pynoo, Sijnave, Voet, and Duyck (2012). The intention-behavior link is crucial in ISacceptance research; yet, the number of studies in which this link is explicitly investigated is very low compared to the total number of acceptance studies. As such, this study is a call for more acceptance studies (in a range of settings, and of populations of users, and with different technologies) in which different aspects of actual technology use are measured and taken into account. Acceptance theories and models may be well established for Information Systems, where typical settings are relatively simple. However, for educational research, where the settings are far more complex, acceptance theories may need some reconsideration and reconceptualization.

\section{References}

Ajzen, I. (1991). The theory of planned behavior. Organizational Behavior and Human Decision Processes, 50, 179-211.

Bagozzi, R. P. (2007). The legacy of the technology acceptance model and a proposal for a paradigm shift. Journal of the Association for Information Systems, 8(4), 244-254.

Bandura, A. (1986). Social foundations of thought and action. Englewood Cliffs, NJ: Prentice Hall.

Bourgonjon, J., De Grove, F., De Smet, C., Van Looy, J., Soetaert, R., \& Valcke, M. (2013). Acceptance of game-based learning by secondary school teachers. Computers \& Education, 67, 21-35.

Brown, S. A., Massey, A. P., Montoya-Weiss, M. M., \& Burkman, J. R. (2002). Do I really have to? User acceptance of mandated technology. European Journal of Information Systems, 11(4), 283-295.

Davis, F. D. (1986). A technology acceptance model for empirically testing new end-user information systems: Theory and results. Massachusetts Institute of Technology.

Davis, F. D., Bagozzi, R. P., \& Warshaw, P. R. (1989). User acceptance of computertechnology - A comparison of 2 theoretical-models. Management Science, 35(8), 982-1003.

De Smet, C., Bourgonjon, J., De Wever, B., Schellens, T., \& Valcke, M. (2012). Researching instructional use and the technology acceptation of learning management systems by secondary school teachers. Computers E Education, 58(2), 688-696.

Devolder, P., Pynoo, B., Sijnave, B., Voet, T., \& Duyck, P. (2012). Framework for user acceptance: Clustering for fine-grained results. Information $\mathcal{E}$ Management, 49(5), 233-239.

Dillon, A., \& Morris, M. G. (1996). User acceptance of new information technology Theories and models. In M. Williams (Ed.). Annual review of information science and technology (Vol. 31, pp. 3-32). Medford, NJ: Information Today.

Duyck, P., Pynoo, B., Devolder, P., Adang, L., Vercruysse, J., \& Voet, T. (2008a). Do hospital physicians really want to go digital? Acceptance of a picture archiving and communication system in a university hospital. Röfo-Fortschritte auf dem Gebiet der Röntgenstrahlen und der Bildgebenden Verfahren, 180, 631-638.

Duyck, P., Pynoo, B., Devolder, P., Voet, T., Adang, L., \& Vercruysse, J. (2008b). User acceptance of a picture archiving and communication system - Applying the unified theory of acceptance and use of technology in a radiological setting. Methods of Information in Medicine, 47(2), 149-156.

Fishbein, M., \& Ajzen, I. (1975). Belief, attitude, intention and behavior: An introduction to theory and research. Reading, MA: Addison-Wesley.

Gong, M., Xu, Y., \& Yu, Y. (2004). An enhanced technology acceptance model for web-based learning. Journal of Information Systems Education, 15(4), 365-374.

Hermans, R., Tondeur, J., van Braak, J., \& Valcke, M. (2008). The impact of primary school teachers' educational beliefs on the classroom use of computers. Computers E' Education, 51, 1499-1509. 
Hu, P. J. H., Clark, T. H. K., \& Ma, W. W. (2003). Examining technology acceptance by school teachers: A longitudinal study. Information \& Management, 41, 227-241.

Ma, W. W. K., Andersson, R., \& Streith, K. O. (2005). Examining user acceptance of computer technology: An empirical study of student teachers. Journal of Computer Assisted Learning, 21(6), 387-395.

Mueller, J., Wood, E., Willoughby, T., Ross, C., \& Specht, J. (2008). Identifying discriminating variables between teachers who fully integrate computers and teachers with limited integration. Computers \& Education, 51, 15231537.

Nistor, N., Gögüs, A., \& Lerche, T. (2013). Educational technology acceptance across national and professional cultures: A European study. Educational Technology Research and Development, 61(4), 733-749.

Nistor, N., \& Heymann, J. O. (2010). Reconsidering the role of attitude in the TAM: An answer to Teo (2009a). British Journal of Educational Technology, 41(6), E142-145.

Nistor, N., Schworm, S., \& Werner, M. (2012). Online help-seeking in communities of practice: Modeling the acceptance of conceptual artifacts. Computers $\mathcal{E}$ Education, 59(2), 774-784.

Pynoo B. (2012). IT-acceptance by autonomous professionals: factors that contribute to success or failure. Ghent University

Pynoo, B., Devolder, P., Duyck, W., van Braak, J., Sijnave, B., \& Duyck, P. (2012a). Do hospital physicians' attitudes change during PACS implementation? A crosssectional acceptance study. International Journal of Medical Informatics, 81(2), 88-97.

Pynoo, B., Devolder, P., Tondeur, J., van Braak, J., Duyck, W., \& Duyck, P. (2011a). Predicting secondary school teachers' acceptance and use of a digital learning environment: A cross-sectional study. Computers in Human Behavior, 27(1), 568-575.

Pynoo, B., Devolder, P., Tondeur, J., van Braak, J., Duyck, W., \& Duyck, P. (2011b). University students' acceptance of a web-based course management system. In T. Teo (Ed.), Technology acceptance in education: Research and issues (pp. 125-144). Rotterdam: Sense Publishers.

Pynoo, B., Devolder, P., Voet, T., Sijnave, B., Gemmel, P., Duyck, W., van Braak, J., \& Duyck, P. (2013). Assessing hospital physicians' acceptance of clinical information systems: A review of the relevant literature. Psychologica Belgica, $53(2), 15-31$.
Pynoo, B., Tondeur, J., van Braak, J., Duyck, W., Sijnave, B., \& Duyck, P. (2012b). Teachers' acceptance and use of an educational portal. Computers E Education, 58(4), 1308-1317.

Rogers, E. M. (1995). Diffusion of innovations. New York: The Free Press.

Sang, G., Valcke, M., van Braak, J., \& Tondeur, J. (2010). Student teachers' thinking processes and ICT integration: Predictors of prospective teaching behaviors with educational technology. Computers \& Education, 54(1), 103-112.

Shapka, J. D., \& Ferrari, M. (2003). Computer-related attitudes and actions of teacher candidates. Computers in Human Behavior, 19(3), 319-334.

Teo, T. (2009a). Is there an attitude problem? Reconsidering the role of attitude in the TAM. British Journal of Educational Technology, 40(6), 1139-1141.

Teo, T. (2009b). Modelling technology acceptance in education: A study of preservice teachers. Computers \& Education, 52, 302-312.

Teo, T., Lee, C. B., \& Chai, C. S. (2008). Understanding pre-service teachers' computer attitudes: Applying and extending the technology acceptance model. Journal of Computer Assisted Learning, 24, 128-143.

Turner, M., Kitchenham, B., Brereton, P., Charters, S., \& Budgen, D. (2010). Does the technology acceptance model predict actual use? A systematic literature review. Information and Software Technology, 52, 463-479.

van Braak, J. (2001). Factors influencing the use of computer mediated communication by teachers in secondary schools. Computers \& Education, 36(1), 41-57.

Venkatesh, V., Brown, S. A., Maruping, L. M., \& Bala, H. (2008). Predicting different conceptualizations of system use: The competing roles of behavioral intention, facilitating conditions, and behavioral expectation. Mis Quarterly, 32(3), 483-502.

Venkatesh, V., Morris, M. G., Davis, G. B., \& Davis, F. D. (2003). User acceptance of information technology: Toward a unified view. Mis Quarterly, 27(3), 425-478.

Wang, W. T., \& Wang, C. C. (2009). An empirical study of instructor adoption of webbased learning systems. Computers \& Education, 53, 761-774.

Warshaw, P. R., \& Davis, F. D. (1985a). Disentangling behavioral intention and behavioral expectation. Journal of Experimental Social Psychology, 21(3), 213-228.

Warshaw, P. R., \& Davis, F. D. (1985b). The accuracy of behavioral intention versus behavioral expectation for predicting behavioral goals. Journal of Psychology. 119(6), 599-602. 